\title{
Prostaglandin E2 involvement in mammalian female fertility: ovulation, fertilization, embryo development and early implantation
}

\author{
Jean Damascene Niringiyumukiza, Hongcai Cai and Wenpei Xiang*
}

\begin{abstract}
Background: Infertility in mammalian females has been a challenge in reproductive medicine. The causes of female infertility include anovulation, ovulated oocyte defects, abnormal fertilization, and insufficient luteal support for embryo development, as well as early implantation. Ovulation induction, in vitro fertilization and luteal support regimens have been performed for decades to increase fertility rates. The identification of proteins and biochemical factors involved in female reproduction is essential to further increase female fertility rates. Evidence has shown that prostaglandins (PGs) might be involved in the female reproductive process, mainly ovulation, fertilization, and implantation. However, only a few studies on individual PGs in female reproduction have been done so far. This review aimed to identify the pivotal role of prostaglandin E2 (PGE2), a predominant PG, in female reproduction to improve fertility, specifically ovulation, fertilization, embryo development and early implantation.

Results: Prostaglandin E2 (PGE2) was shown to play a relevant role in the ovulatory cascade, including meiotic maturation, cumulus expansion and follicle rupture, through inducing ovulatory genes, such as Areg, Ereg, Has2 and Tnfaip6, as well as increasing intracellular cAMP levels. PGE2 reduces extracellular matrix viscosity and thereby optimizes the conditions for sperm penetration. PGE2 reduces the phagocytic activity of polymorphonuclear neutrophils (PMNs) against sperm. In the presence of PGE2, sperm function and binding capacity to oocytes are enhanced. PGE2 maintains luteal function for embryo development and early implantation. In addition, it induces chemokine expression for trophoblast apposition and adhesion to the decidua for implantation.

Conclusion: It has been shown that PGE2 positively affects different stages of female fertility. Therefore, PGE2 should be taken into consideration when optimizing reproduction in infertile females. We suggest that in clinical practice, the administration of non-steroidal anti-inflammatory drugs, which are PGE2 synthesis inhibitors, should be reasonable and limited in infertile women. Additionally, assessments of PGE2 protein and receptor expression levels should be taken into consideration.
\end{abstract}

Keywords: Blastocyst, Cumulus, Chemokine, Extracellular matrix, Fertilization, Implantation, Prostaglandin E2

\footnotetext{
* Correspondence: wpxiang2010@gmail.com

Family Planning Research Institute/Center of Reproductive Medicine, Tongji

Medical College, Huazhong University of Science and Technology, Wuhan

430030, Hubei, China
}

(c) The Author(s). 2018 Open Access This article is distributed under the terms of the Creative Commons Attribution 4.0 International License (http://creativecommons.org/licenses/by/4.0/), which permits unrestricted use, distribution, and reproduction in any medium, provided you give appropriate credit to the original author(s) and the source, provide a link to the Creative Commons license, and indicate if changes were made. The Creative Commons Public Domain Dedication waiver (http://creativecommons.org/publicdomain/zero/1.0/) applies to the data made available in this article, unless otherwise stated. 


\section{Background}

Many couples suffer from infertility, which is a big challenge not only to them but also to their family, endocrinology and infertility specialists, and embryologists. Different assisted reproductive techniques (ART) are used to enhance fertility rates. However, despite the constant development of sophisticated equipment and procedures, infertility treatment is still complicated and has a low success rate.

Previous studies have provided evidence that prostaglandins (PGs) may play a pivotal role in female reproduction, particularly in ovulation, implantation, and menstruation; however, the mechanisms involved remain elusive $[1,2]$. The non-steroidal anti-inflammatory drugs (NSAIDs) aspirin and indomethacin, which inhibit cyclooxygenase (COX), were reported to have adverse effects on gonadotropin-releasing hormone release, ovulation, fertilization and luteolysis [3].

There are five types of PGs (also known as prostanoids): prostaglandin E2 (PGE2), prostaglandin D2 (PGD2), prostaglandin PGF2 $\alpha$ (PGF2 Alfa), prostaglandin PGI2 (PGI2) and thromboxane (THA2). These are ubiquitously secreted, mostly from inflamed cells. PGs are synthesized from arachidonic acid by the key enzyme COX, also called prostaglandin synthase protein (PTGS) [4, 5]. Each PG has a specific influence and mechanism in the female reproductive system. However, it is possible that the different PGs also act in a synergistic way to fulfill their biological functions. Although the role of PGs in the female reproductive system has been already described, little is known about the individual PGs as separate functional entities in female reproduction.

PGE2 is the most common and substantial PG found in animal species. A wide range of receptor (EP, also noted as PTGER) subtypes (EP1, EP2, EP3 and EP4) that are bound by PGE2 have a multitude of signal transduction properties $[6,7]$. The essential role of PGE2 production in female fertility has been suggested in previous studies [7, 8]. Experiments with PGE2 receptor type2 (EP2)-deficient mice showed disturbances in ovulation, fertilization, embryo development and implantation $[9,10]$. Due to the predominance of PGE2 and its broad biological functions mediated by its different types of receptors, this review summarizes the role and mechanisms of PGE2 in ovulation, fertilization, embryo development and successful early implantation (Fig. 1).

\section{Results}

\section{PGE2 involvement in the ovulation cascade}

The luteinizing hormone (LH) surge was demonstrated to be responsible for oocyte cumulus expansion and meiotic maturation $[11,13]$. However, the small amounts of $\mathrm{LH}$ receptors expressed in cumulus cells and in the oocyte [12] suggest that LH acts via other mediators. PGE2 is one of the mediators found to promote oocyte cumulus expansion and maturation [14]. Previous studies reported that inhibiting PGE2 production in follicles or genetically knocking out PGE2 and PGE2 receptor expression could prevent ovulation [7, 8]. However, the mechanisms of PGE2 in oocyte cumulus expansion and meiotic maturation remain elusive.

\section{PGE2 enhances cumulus expansion}

Ovulation requires adequate cumulus cell expansion to enable cumulus-oocyte complex (COC) detachment from the follicle wall and follicle rupture to release the oocyte into the oviduct. It was found that the LH surge increases PGE2 levels in the dominant follicle to modulate the action of gonadotropin for cumulus cell expansion and the expression of proteases associated with follicle rupture [15-18]. Female mice deficient in EP2, a PGE2 receptor, presented with abnormal cumulus cell expansion and unruptured follicles, which resulted in infertility or subfertility $[7,19]$.

The essential genes that are induced in COCs and are responsible for expansion include the following: oocyte maturation genes of epidermal growth factor (EGF)-like factors, such as amphiregulin (Areg), epiregulin (Ereg) and betacellulin (Btc) [20, 21]; and matrix-forming and stabilizing elements, such as hyaluronan synthase 2 (Has2) and tumor necrosis factor $\alpha$-induced protein 6 (Tnfaip6) [20, 22]. Studies have shown that PGE2 up-regulates the expression of many of these genes, including Areg, Ereg, Has2 and Tnfaip6, in granulosa and cumulus cells via its receptor EP2 $[21,23]$. Moreover, there is evidence that the cAMP pathway induces the expression of the cumulus expansion-related genes Has 2 and Tnfaip6 in cumulus cells [4] and that PGE2 increases cAMP concentrations in cumulus cells during ovulation [23]; these findings suggest a direct role of PGE2 in cumulus expansion via these growth factors. The role of the protein kinase $\mathrm{B}$ and mitogen-activated protein kinases3/1 (PKB-MAPK3/1) pathway in cumulus expansion has also been documented [24, 25], and PGE2 was found to activate this pathway for cumulus cell expansion and meiosis resumption [26].

\section{PGE2 has been involved in oocyte meiotic maturation}

PGE2 was found to be involved in not only cumulus expansion but also in meiotic maturation [27]. Cyclic adenosine monophosphate (cAMP) is a well-known mediator of meiotic maturation. PGE2 increases cAMP production in follicles, resulting in the maturation and cumulus expansion of oocytes [23, 28]. The PGE2 receptors EP2 and EP4, which are predominant in cumulus and granulosa cells [29], can increase intracellular cAMP levels when they are coupled to adenylate cyclase $[30,31]$. In an in vitro study using mouse oocytes, treatment with an agonist selective for EP2 and EP4 increased cAMP production and subsequently increased ovulation rates [32], whereas 


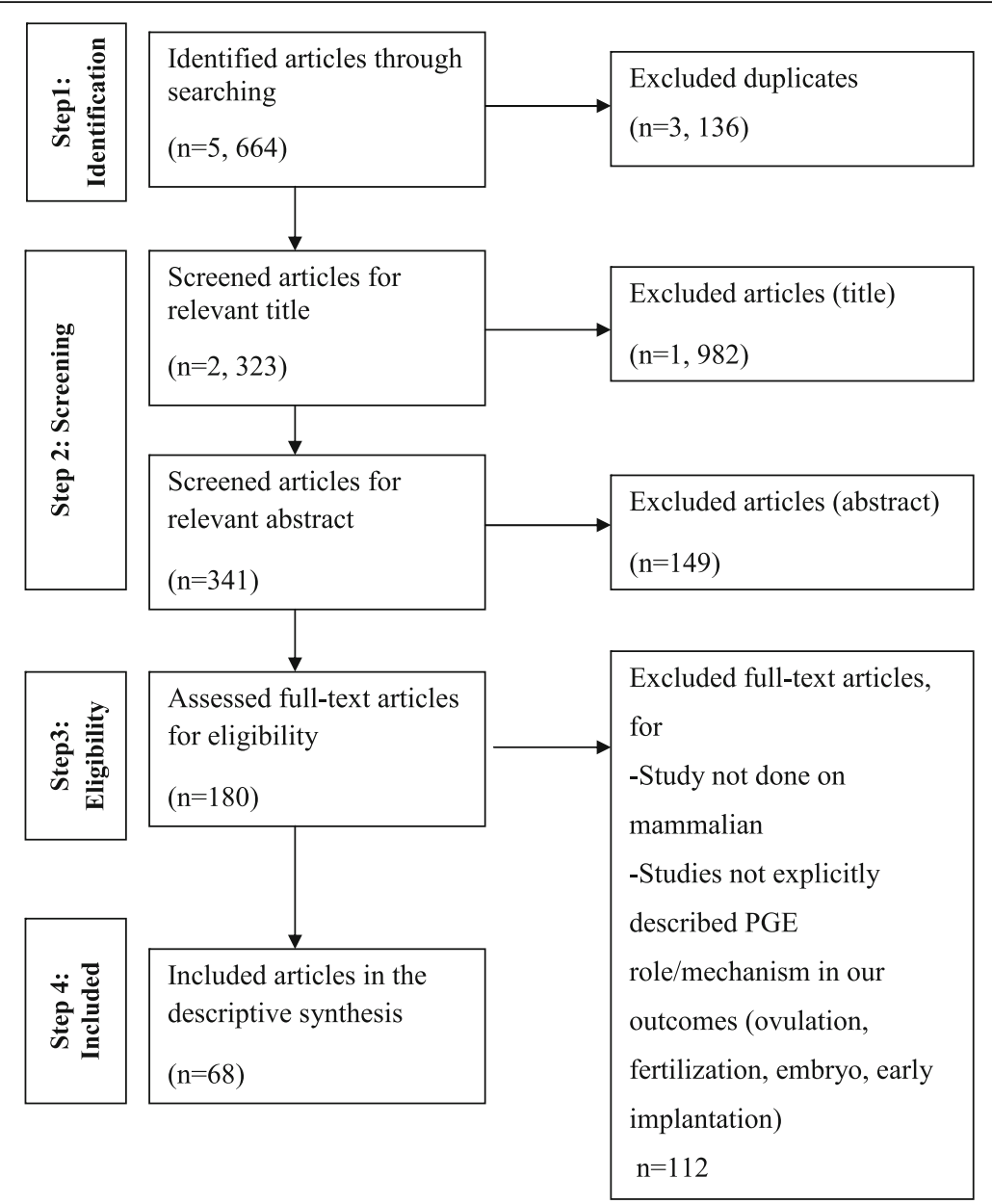

Fig. 1 Selection of articles

the genetic manipulation of genes encoding EP2 and EP4 resulted in the inhibition of meiotic maturation and $\mathrm{cu}-$ mulus expansion [10,33]. Several factors are responsible for maintaining spindle integrity during meiotic maturation. MAPK regulates spindle integrity during the meiotic maturation of oocytes [34, 35]. MAPK activity depends on phosphorylation. PGE2 was found to be responsible for the phosphorylation of MAPK [36], suggesting that PGE2 activates MAPK and indirectly induces the meiotic maturation of oocytes.

PGE2 was thought to mediate LH signals for meiotic maturation. Angiotensin II stimulation by LH has been reported to promote the meiotic maturation of oocytes by blocking the inhibitory effect of theca cells $[37,38]$. It was demonstrated that the effects of angiotensin II in this process are mediated by PGE2 [39-41]. In an in vitro bovine oocyte study, indomethacin supplementation blocked the meiotic maturation of bovine oocytes induced by angiotensin II, whereas PGE2 treatment restored meiotic maturation to levels comparable to those induced by angiotensin II [39]. Human chorionic gonadotropin (hCG), a substitute for $\mathrm{LH}$ that stimulates oocyte maturation and ovulation in assisted reproduction, was reported to increase PGE2 and ovulatory gene expression through prostaglandin transport (PGT) in human granulosa cells [42].

Even though LH and PGE2 were shown to trigger cumulus expansion and meiotic maturation separately [11-13], according to the above findings, we suggest similarity and synergetic effects between LH and the PGE2 pathways in regulating cumulus expansion and meiotic maturation. First, LH and PGE2 receptors are members of the G protein-coupled receptor (GPCR) family, and they trigger the ovulation process via activating adenylate cyclases to increase cAMP concentrations $[23,43,44]$ for the synthesis of EGF-like factors, including Areg and Ereg, in granulosa and cumulus cells [23, 44-46]. Because the PGE2/cAMP pathway has been studied in meiotic maturation [23, 28], but not in the stimulation of Areg and Ereg secretion, we hypothesize that PGE2 induces cAMP pathways to stimulate EGF-like growth factors in cumulus and granulosa cells via its receptors (the same as LH); we propose this since these growth factors are positively 
involved in both cumulus expansion and oocyte meiotic maturation (Fig. 2).

\section{PGE2 modulates the fertilization process PGE2 regulates cumulus ECM disassembly for sperm penetration into the oocyte}

Cumulus cells synthesize and secrete extracellular matrices (ECMs) composed of mostly hyaluronan deposited in the intercellular space $[47,48]$. ECM deposition in the inter-cumulus cell space leads to cumulus expansion, increases ECM viscosity and confers resistance capacity against biochemical and mechanical stress to the cumulus ECM. Chemokines were reported to modulate cumulus ECM consistency [49-51]. It has been demonstrated that upon ovulation, cumulus cells secrete various factors, including chemokine receptors and chemokines, such as CCL7, CCL2, and CCL9, which can increase the ECM viscosity to protect the oocyte from mechanical stress $[49,51]$. The increased ECM consistency in cumulus cells by CCL-CCR signals impedes the passage of sperm and prevents fertilization [3, 49]. PGE2-induced activation of the cAMP pathway [50] disassembles and attenuates the ECM consistency $[7,50]$ by inhibiting the secretion of the chemokines CCL7 and CCL2 [50, 52]; these effects create a free space for sperm penetration.

In addition, interleukin-1 $\beta$ (IL-1 $\beta$ ) stimulates the secretion of CCL2 in different cells $[53,54]$ and granulosa cells [55]. Given that cumulus cells are derived from granulosa cells, we hypothesize that IL-1 $\beta$ also stimulates CCL2 secretion in cumulus cells. It was found that PGE2 inhibits IL-1 $\beta$ in the myometrial cells of pregnant women [56], suggesting that PGE2 also inhibits the expression of CCL2 stimulated by IL- $1 \beta$. Increased IL- $1 \beta$ expression was identified in cumulus cells lacking the PGE2 receptor EP2 [49], and we suspect a subsequent increase in CCL2 expression in these cells lacking PGE2 receptors. Taken together, we suggest that PGE2 acts via EP2 as a negative regulator of the chemokines CCL7 and CCL2 in the cumulus ECM to enhance ECM disassembly for sperm penetration and subsequent fertilization (Fig. 3a, b).

\section{PGE2 protects sperm against phagocytosis in the oviduct}

Neutrophils are mobilized in oviduct in response to the presence of sperm, a process resembling classical

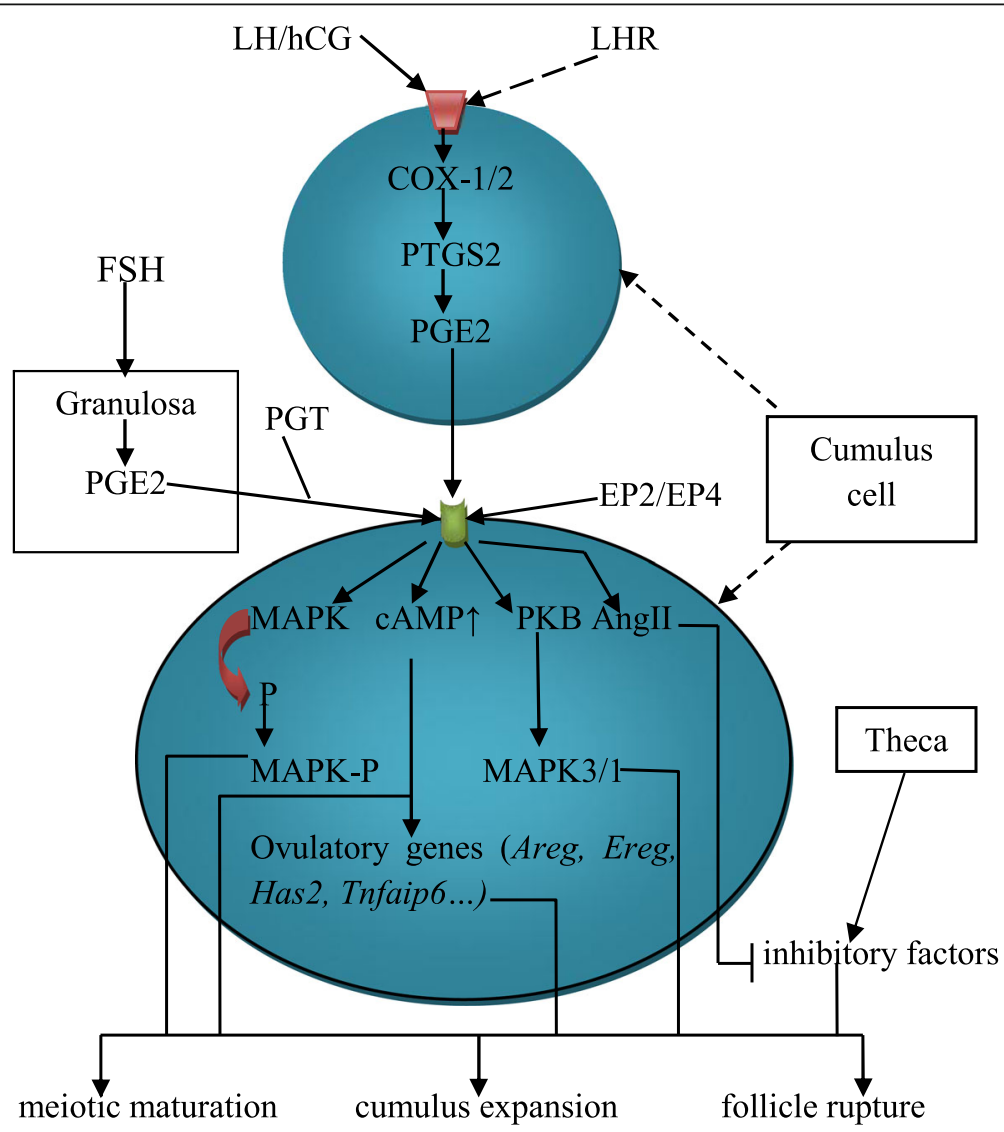

Fig. 2 Ovulatory cascade. LH/hCG induces PGE2 synthesis and secretion in cumulus cells. Additionally, granulosa cells under FSH stimulation release PGE2, which is coupled with PGT and transported to the cumulus cell membrane to bind the PGE2 receptors EP2 and EP4. Via these receptors, PGE2 induces MAPK phosphorylation, increases intracellular CAMP levels and activates the PKB/MAPK3/1 pathway to stimulate ovulatory gene expression. Furthermore, PGE2 stimulates Angiotensin II to inhibit the inhibitory factors against meiotic maturation, released by theca cells 


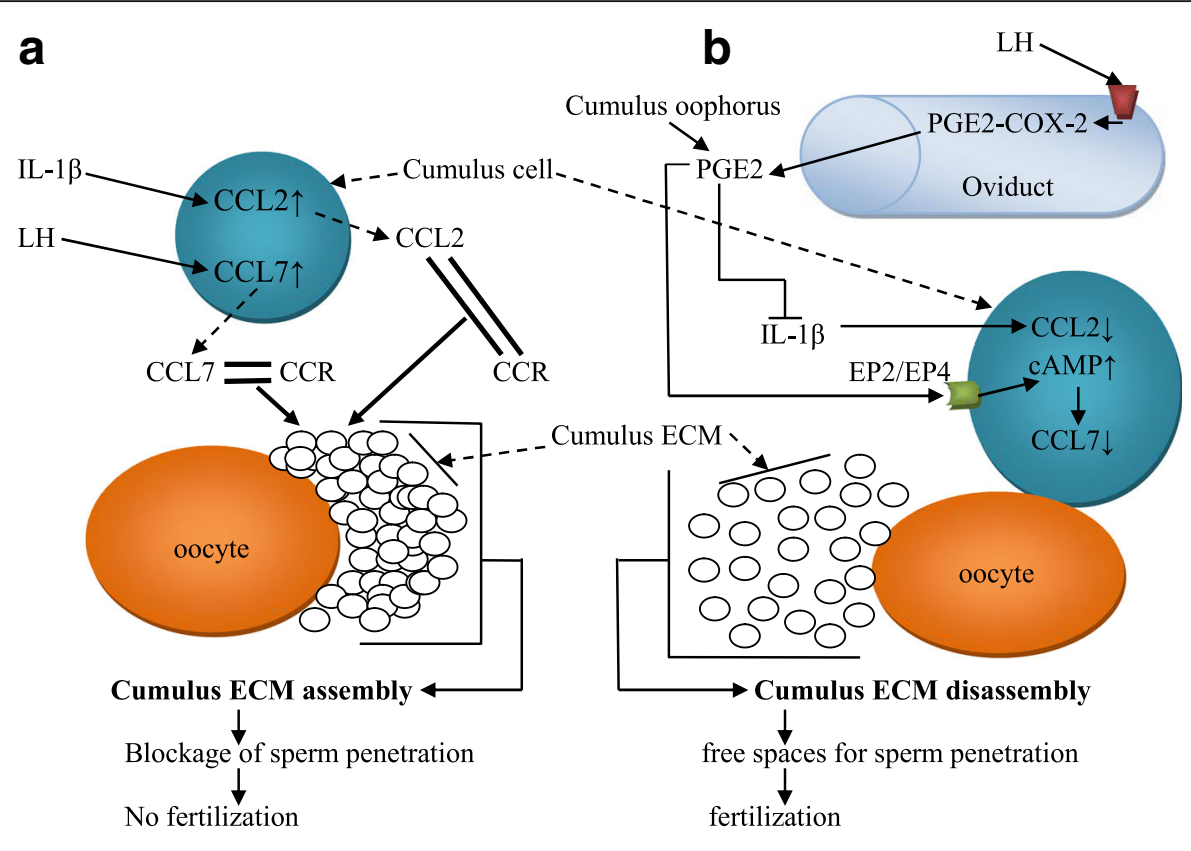

C

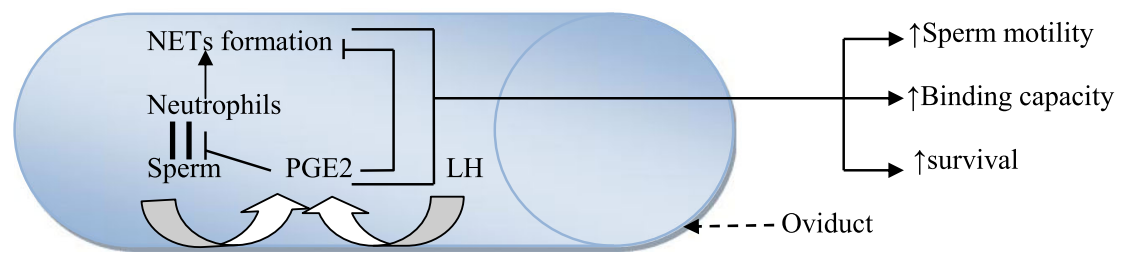

Fig. 3 PGE2 in the fertilization process. PGE2 disassembles the cumulus ECM for sperm penetration and inhibits the phagocytic activity of PMNs against sperm. a Cumulus ECM assembly: In cumulus cells, LH and IL-1 $\beta$ respectively induce the expression of the chemokines CCL7 and CCL2. CCL7 and CCL2 bind the chemokine receptor CCR to induce cumulus cell-ECM assembly. b Cumulus cell-ECM disassembly: Upon ovulation, there is an increased level of PGE2 secreted by oviduct epithelial cells and the cumulus oophorus. PGE2 inhibits IL-1 $\beta$ and increases intracellular cAMP concentrations, respectively resulting in decreased expression levels of CCL2 and CCL7; these actions subsequently result in the disassembly of the cumulus ECM. The disassembly of the cumulus ECM leaves a free space for sperm penetration into the oocyte for fertilization. $\mathbf{c}$ In the oviduct, sperm binding to epithelial cells, as well as LH stimulation, induce PGE2 secretion. The released PGE2 inhibits neutrophil binding to the sperm and NET formation. Sperm in the presence of PGE2 have increased mobility, survival and binding capacity to the oocyte

inflammation [57-59]. When protective signals become ineffective, the neutrophils fight against the sperms and reduce their motility and fertilization potential [60-62].

PGE2 exerts immunosuppressive activity [63], which inhibits the phagocytosis of sperm by neutrophils and macrophages $[64,65]$. In the oviduct, in addition to the PGE2 secreted after epithelial cell stimulation by LH [66], it was found that sperm binding to the epithelial cells also induces PGE2 release [67], suggesting an auto-defense mechanism exerted by sperm in the oviduct. Via its receptor EP2, PGE2 may protect sperm from the phagocytic activity of polymorphonuclear neutrophils (PMNs) in the oviduct [68-70]. Neutrophils phagocytize spermatozoa either through cell attachment or by entrapping them in neutrophil extracellular traps (NETs) [71, 72]. A previous study demonstrated that PGE2 inhibits NET formation [73]. We suggest that the immunosuppressive potential of
PGE2 and its inhibition of NET formation may result in enhanced sperm survival and higher motility and binding capacity of sperm in the oviduct, which subsequently increase the fertilization rate (Fig. 3c).

\section{Essential role of PGE2 in embryo development and early implantation}

Various factors mediate the cell proliferation, cleavage and survival of embryonic cells, as well as blastocyst formation and hatching. An embryo in the endometrium stimulates signals that have direct or indirect effects on its development and implantation. In embryos, gradually increasing levels of PGE2 from a 2-cell embryo to blastocyst were identified [74]. PGE2 was demonstrated to promote blastocyst hatching and enhance trophoblast proliferation after embryo transfer [75, 76]. PGE2 is considered to be a mitogenic, anti-apoptotic and angiogenic factor for cell 
proliferation and survival in other cells [77, 78], which suggests that PGE2 exerts these effects in embryo development, thus enhancing embryonic and trophoblast cell proliferation and survival for implantation (Fig. 4).

\section{PGE2 maintains luteal function for early embryo development and implantation}

After ovulation, mechanisms that protect the corpus luteum from regression should be initiated to stimulate the continuous production of factors protecting and promoting embryo development and early implantation. An increase in PGE2 biosynthesis and signaling in the uterus during the luteal phase was noted in sheep [79] and pig models [80], suggesting the role of this PG during early pregnancy. Through its receptor EP2, PGE2 induces the expression of $\mathrm{LH}$ receptors on the corpus luteum, resulting in an increase in progesterone (P4) synthesis [81, 82]. Previous studies reported that decreased blood flow to the luteal-containing ovary and decreased progesterone production result in luteolysis [83]. Blood flow has to be maintained for incoming biochemical factors, including LH, E2 and PGE2, to stimulate the corpus luteum to synthesize and secrete various factors, mostly P4, as well as to disseminate the secreted factors in the systemic system for embryo development and early implantation [84]. Via its receptor EP4, PGE2 was shown to enhance utero-ovarian blood circulation by increasing adenylate cyclase (AC) activity, which in turn increases nitric oxide synthase (OS) activity to increase synthesis and nitric oxide (NO) release, a vasodilator [85].

Interferon tau (IFN-t) was reported to reverse the PG secretion profile in endometrial cells during early pregnancy, thus resulting in increased PGE2 secretion and decreased PGF2a secretion [86, 87]. The increased PGE2/PGF2 $\alpha$ ratio during early pregnancy is thought to prevent luteolysis and to support the luteal function for embryo development and successful implantation. It was reported that embryos secrete $17-\beta$ estradiol (E2) to stimulate continuous $\mathrm{P} 4$ production by the corpus luteum $[88,89]$. The roles of embryo-secreted estradiol would be anti-luteolytic and lyteoprotectant, which are properties of PGE2. Previous studies demonstrated a simultaneous increase in E2 secretion by the embryo [90] and a shift from PGF2 $\alpha$ to PGE2 secretion with a subsequent increase in the PGE2/PGF2 $\alpha$ ratio during early pregnancy [91, 92]. Given the spatio-temporal pattern of E2 and PGE2 secretion and their localization, we hypothesize that there is an interaction between E2 and PGE2 to inhibit luteolysis. Moreover, E2 was shown to increase PGE2 production by stimulating PTGS2 secretion, which potentiates its activity through increasing the expression of EP2 [93]; E2 also decreases PGF2 $\alpha$ production by inhibiting the secretion of PGFS (prostaglandin F2alpha synthase) and carbonyl reductase 1 (CBR1) [93], enzymes involved in PGF2 $\alpha$ secretion [94-96].

We hypothesize that PGE2 exerts its anti-luteolytic properties to protect and enhance embryo development and early implantation by inducing LH receptors on the corpus luteum for continuous progesterone secretion, by increasing nitric oxide $(\mathrm{NO})$ synthesis and production to maintain adequate utero-ovarian blood flow and by mediating the effects of E2 and IFN-t to stimulate P4 secretion (Fig. 5a).

\section{PGE2 stimulates chemokines for trophoblast apposition and adhesion to the maternal decidua}

Different signals, including chemokines and chemokine receptors, produced in the endometrium are essential for embryo development and early implantation. Previous studies found that PGE2 modulates the expression of CXCR4, which is a receptor for the chemokine CXCL12, in hematopoietic stem cells [97] and stromal cells of the endometrium [98]. Embryonic signals were shown to regulate the expression of

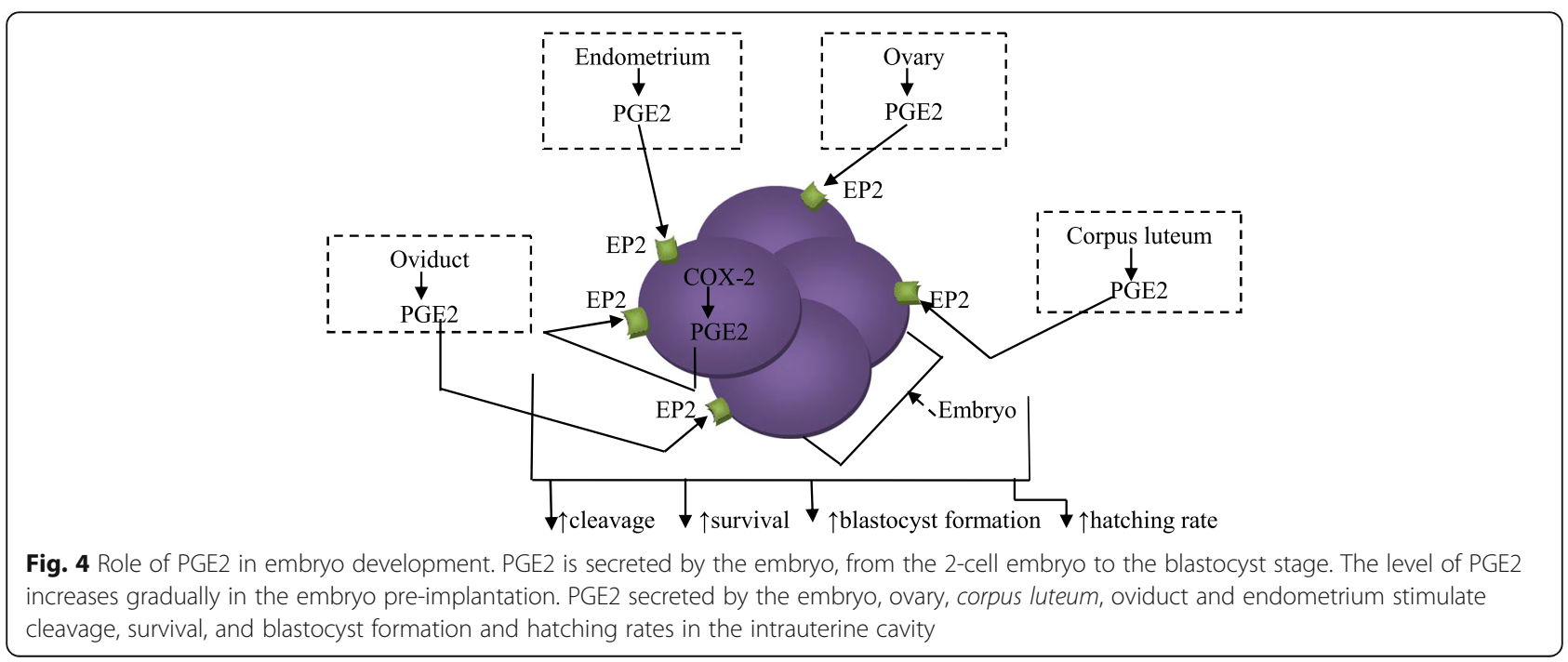



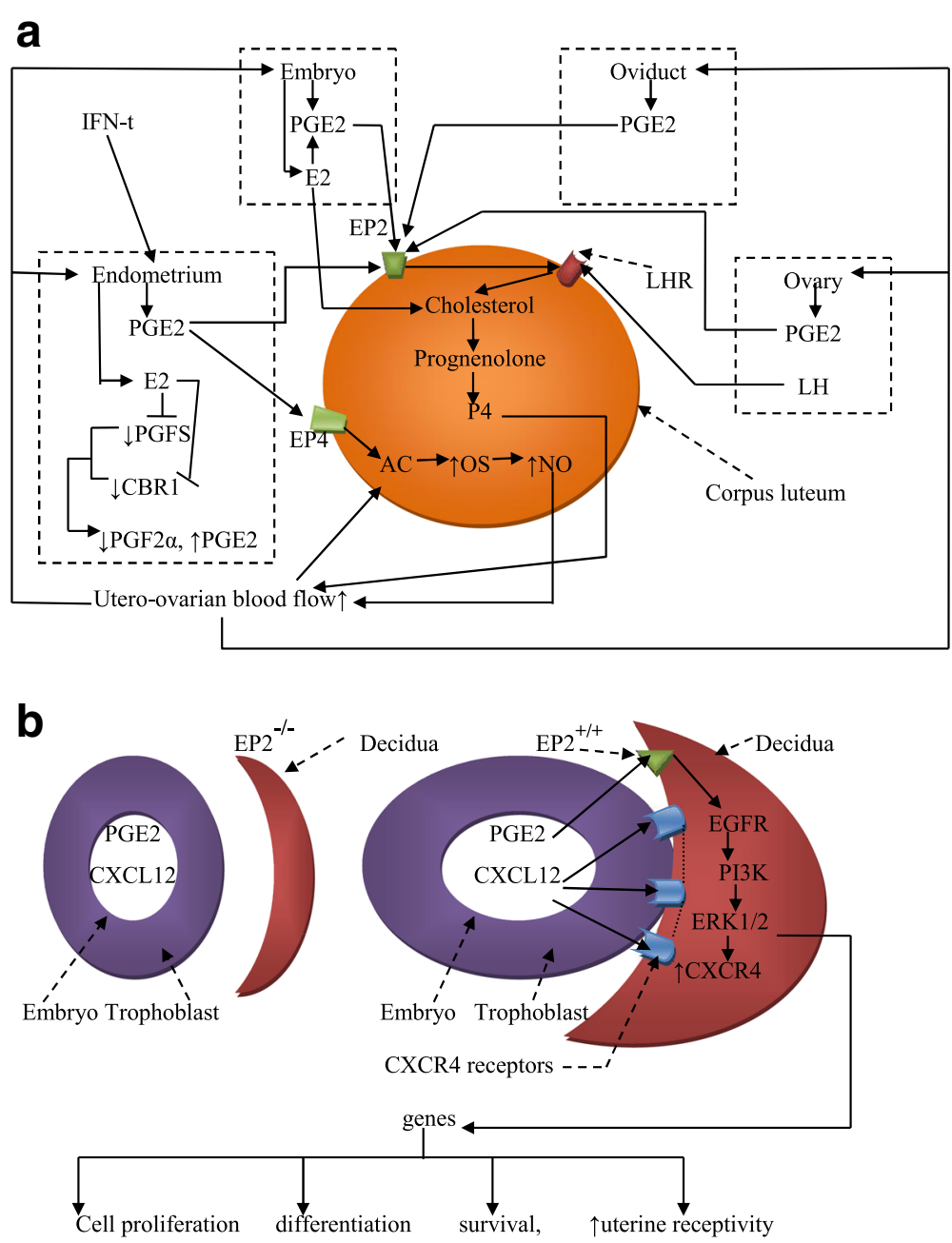

Fig. 5 a PGE2 mediates early implantation. a Upon ovulation, PGE2 is secreted by the following reproductive organs: ovaries, endometrium and oviduct, as well as the embryo. EP2 induces LH receptor expression on the corpus luteum to secrete P4 and stimulate its continuous release into the in utero-ovarian circulation. P4 exerts positive feedback to the ovaries, endometrium and oviduct to recognize and maintain the ongoing implantation and embryo development. Via EP4, PGE2 increases the activity of adenylate cyclase (AC) and nitric oxide synthase (OS) successivelyto increase synthesis and nitric oxide (NO) release. NO, a vasodilator, increases the utero-ovarian blood flow and the concentration of pro-pregnancy factors. Additionally, E2 secreted by the embryo and endometrium stimulates PGE2/EP2 to increase the secretion of P4 and inhibits PGFS and CRB1, enzymes involved in the synthesis of PGF2a, an antagonist of PGE2. $\mathbf{b}$ In endometrial cells with EP2 receptors, PGE2 stimulates the expression of CXCR4 via the EGFR-PI3K/ERK1/2 pathway. CXCR4 is bound by the chemokine CXCL12, which is secreted by the embryo. PGE2 also stimulates the EGFR-PI3K/ERK1/2 pathway to induce the expression of genes involved in cell proliferation, differentiation and uterine receptivity

CXCR4 receptors in the endometrium [99], and the chemokine CXCL12 was identified in blastocysts [100].

PGE2 secreted by the embryo [101] binds to EP2 receptors in the endometrium to stimulate CXCR4 via the epidermal growth factor receptor (EGFR)-phosphatidyl inositol-3 kinase (PI3K) and extracellular signal-regulated kinase (ERK1/2) pathways [102]. The EGFR, PI3K and ERK1/2 pathways were shown to mediate early embryo implantation by inducing the expression of genes involved in cell growth, differentiation and uterine receptivity [103-105]. Moreover, high levels of CXCR4 expression were found in endometrium stromal cells at the apposition site of the embryo during the implantation window
[106]. Furthermore, the PI3K/ERK1/2 pathways are known as pro-survival pathways that enhance the growth, proliferation, differentiation and survival of embryonic and endometrial cells [107]. We hypothesize that PGE2 secreted by embryos influences the apposition, adhesion and invasion of trophoblastic cells to the decidua by stimulating the expression of the chemokine CXCR4 receptor at the implantation site via the EP2, EGFR, PI3K and ERK1/2 pathways and/or by stimulating the synthesis of the chemokine CXCL12, which in turn will bind to CXCR4 receptors. In addition, we suggest that PGE2 uses the PI3K/ERK1/2 pathways to promote embryonic growth, proliferation, differentiation and survival, as well 
as endometrial cell growth, proliferation and differentiation in decidual cells.

The above findings indicate that PGE2 is essential for enhancing pre-implantation embryo development and early implantation. However, other mechanisms need to be further investigated (Fig. 5b).

\section{Conclusion}

This review explored the involvement of PGE2 in cumulus cell expansion and meiotic maturation; in these processes, PGE2 either mediates LH signaling or directly acts on EGFs, such as Areg and Ereg, and matrix forming and stabilizing factors, such as Has2 and Tnfaip6. PGE2 production in the oviduct reduces cumulus ECM viscosity around the oocyte for sperm penetration, protects the sperm from the phagocytic activity of neutrophils and enhances sperm survival, binding capacity, motility and function to promote successful fertilization. In addition, the effects of PGE2 on embryo development to a blastocyst, hatching and successfully implantation were demonstrated through the maintenance of luteal function and the induction and stimulation of chemokines for trophoblast proliferation, apposition and adhesion to the maternal decidua.

We suggest that in clinical practice, the administration of non-steroidal anti-inflammatory drugs, which are inhibitors of PGE2 synthesis, should be reasonable and limited in infertile women. Additionally, assessments of PGE2 protein and receptor expression levels should be taken into consideration in infertile women. However, we recommend more studies on the mechanisms of PGE2 in female reproduction and randomized clinical trials to draw definite conclusions to support this hypothesis.

\begin{abstract}
Abbreviations
AC: Adenylate cyclase; Areg: Amphiregulin; CAMP: Cyclic adenosine monophospate; CBR1: Carbonyl reductase 1; CCL2: Chemokine ligand 2; CCL7: Chemokine ligand 7; CCR: Chemokine receptor; COX: Cyclo-oxygenase; CXCL12: Chemokine 12; CXCR4: Chemokine receptor type 4; E2: Estradiol; ECM: Cumulus extracellular matrix; EGF: Epidermal growth factor; EGFR: Epidermal growth factor receptor; EP2: Prostaglandin E2 receptor type 2; EP4: Prostaglandin E2 receptor type 4; Ereg: Epiregulin; ERK1/2: Extracellular-regulated kinase 1and 2; FSH: Follicle stimulating hormone; Has2: Hyaluronan synthase 2; hCG: Human chorionic gonadotropin; IFN-t: Interferon-tau; IL-1ß: Interleukin-1 beta; LH: Luteinizing hormone; MAPK3/1: Mitogen-activated protein kinases 3 and 1; NETs: Neutrophil extracellular traps; NO: Nitric oxide; OS: Oxide synthase; P4: Progesterone; PG: Prostaglandin; PGE2: Prostaglandin E2; PGF2a: Prostaglandin F2 alfa; PGFS: Prostaglandin F2 alfa synthase; PGT: Prostaglandin transport; PI3K: Phosphatidyl inositol-3 kinase; PKB: Protein kinase B; PTGS: Prostaglandin synthase; Tnaif6: Tumor necrosis factor $a$-induced protein 6
\end{abstract}

\section{Availability of data and materials}

All data generated or analyzed during this study are included.

\section{Authors' contributions}

JDN and HC were involved in the conception and design of the study, data acquisition, analysis and manuscript drafting. JDN and WX were involved with data acquisition and analysis. All authors read and approved the final manuscript.

Ethics approval and consent to participate

Not applicable as this is a review article based on earlier published work.
Competing interests

The authors declare that they have no competing interests.

\section{Publisher's Note}

Springer Nature remains neutral with regard to jurisdictional claims in published maps and institutional affiliations.

Received: 20 December 2017 Accepted: 20 April 2018

Published online: 01 May 2018

\section{References}

1. Jabbour HN, Sales KJ. Prostaglandin receptor signalling and function in human endometrial pathology. Trends Endocrinol Metab. 2004;15(8):398-404.

2. Kang J, et al. Expression of human prostaglandin transporter in the human endometrium across the menstrual cycle. J Clin Endocrinol Metab. 2005; 90(4):2308-13.

3. Sugimoto Y, Inazumi T, Tsuchiya S. Roles of prostaglandin receptors in female reproduction. J Biochem. 2015;157(2):73-80.

4. Helliwell RJ, Adams LF, Mitchell MD. Prostaglandin synthases: recent developments and a novel hypothesis. Prostaglandins Leukot Essent Fatty Acids. 2004;70(2):101-13.

5. Seo MJ, Oh DK. Prostaglandin synthases: molecular characterization and involvement in prostaglandin biosynthesis. Prog Lipid Res. 2017; 66:50-68.

6. Fujino H, Xu W, Regan JW. Prostaglandin E2 induced functional expression of early growth response factor-1 by EP4, but not EP2, prostanoid receptors via the phosphatidylinositol 3-kinase and extracellular signal-regulated kinases. J Biol Chem. 2003;278(14):12151-6.

7. Hizaki $\mathrm{H}$, et al. Abortive expansion of the cumulus and impaired fertility in mice lacking the prostaglandin E receptor subtype EP(2). Proc Natl Acad Sci U S A. 1999;96(18):10501-6.

8. Lim H, et al. Multiple female reproductive failures in cyclooxygenase 2-deficient mice. Cell. 1997;91 (2):197-208.

9. Chakraborty I, et al. Developmental expression of the cyclo-oxygenase-1 and cyclo-oxygenase-2 genes in the peri-implantation mouse uterus and their differential regulation by the blastocyst and ovarian steroids. J Mol Endocrinol. 1996;16(2):107-22.

10. Matsumoto $\mathrm{H}$, et al. Diversification of cyclooxygenase-2-derived prostaglandins in ovulation and implantation. Biol Reprod. 2001;64(5):1557-65.

11. Amsterdam A, Rotmensch S. Structure-function relationships during granulosa cell differentiation. Endocr Rev. 1987;8(3):309-37.

12. Peng $X R$, et al. Localization of luteinizing hormone receptor messenger ribonucleic acid expression in ovarian cell types during follicle development and ovulation. Endocrinology. 1991;129(6):3200-7.

13. Amsterdam A, Rotmensch S, Ben-Ze'ev A. Coordinated regulation of morphological and biochemical differentiation in a steroidogenic cell: the granulosa cell model. Trends Biochem Sci. 1989;14(9):377-82.

14. Sirois J, et al. Cyclooxygenase-2 and its role in ovulation: a 2004 account. Hum Reprod Update. 2004;10(5):373-85.

15. Duffy DM, Stouffer RL. Follicular administration of a cyclooxygenase inhibitor can prevent oocyte release without alteration of normal luteal function in rhesus monkeys. Hum Reprod. 2002;17(11):2825-31.

16. Duffy DM, Stouffer RL. The ovulatory gonadotrophin surge stimulates cyclooxygenase expression and prostaglandin production by the monkey follicle. Mol Hum Reprod. 2001;7(8):731-9.

17. Murdoch WJ, Hansen TR, McPherson LA. A review-role of eicosanoids in vertebrate ovulation. Prostaglandins. 1993;46(2):85-115.

18. Duffy DM, Dozier BL, Seachord CL. Prostaglandin dehydrogenase and prostaglandin levels in periovulatory follicles: implications for control of primate ovulation by prostaglandin E2. J Clin Endocrinol Metab. 2005; 90(2):1021-7.

19. Ochsner SA, et al. Decreased expression of tumor necrosis factor-alphastimulated gene 6 in cumulus cells of the cyclooxygenase-2 and EP2 null mice. Endocrinology. 2003;144(3):1008-19.

20. Park JY, et al. EGF-like growth factors as mediators of $\mathrm{LH}$ action in the ovulatory follicle. Science. 2004;303(5658):682-4.

21. Liu Z, et al. Targeted disruption of Mapk14 (p38MAPKalpha) in granulosa cells and cumulus cells causes cell-specific changes in gene expression profiles that rescue COC expansion and maintain fertility. Mol Endocrinol. 2010;24(9):1794-804. 
22. Fulop C, et al. Impaired cumulus mucification and female sterility in tumor necrosis factor-induced protein-6 deficient mice. Development. 2003; 130(10):2253-61.

23. Ben-Ami I, et al. PGE2 up-regulates EGF-like growth factor biosynthesis in human granulosa cells: new insights into the coordination between PGE2 and LH in ovulation. Mol Hum Reprod. 2006;12(10):593-9.

24. Fan HY, et al. MAPK3/1 (ERK1/2) in ovarian granulosa cells are essential for female fertility. Science. 2009;324(5929):938-41.

25. Prochazka R, Blaha M, Nemcova L. Signaling pathways regulating FSH- and amphiregulin-induced meiotic resumption and cumulus cell expansion in the pig. Reproduction. 2012;144(5):535-46.

26. Blaha $\mathrm{M}$, et al. Prostaglandin E2 stimulates the expression of cumulus expansion-related genes in pigs: the role of protein kinase B. Prostaglandins Other Lipid Mediat. 2017;130:38-46.

27. Yamashita Y, et al. Positive feedback loop between prostaglandin E2 and EGF-like factors is essential for sustainable activation of MAPK3/1 in cumulus cells during in vitro maturation of porcine cumulus oocyte complexes. Biol Reprod. 2011;85(5):1073-82.

28. Downs SM, Hunzicker-Dunn M. Differential regulation of oocyte maturation and cumulus expansion in the mouse oocyte-cumulus cell complex by site-selective analogs of cyclic adenosine monophosphate. Dev Biol. 1995;172(1):72-85.

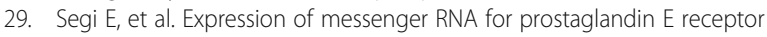
subtypes EP4/EP2 and cyclooxygenase isozymes in mouse periovulatory follicles and oviducts during superovulation. Biol Reprod. 2003;68(3):804-11.

30. Sugimoto $Y$, Narumiya $S$, Ichikawa A. Distribution and function of prostanoid receptors: studies from knockout mice. Prog Lipid Res. 2000;39(4):289-314.

31. Narumiya S, FitzGerald GA. Genetic and pharmacological analysis of prostanoid receptor function. J Clin Invest. 2001;108(1):25-30.

32. Duffy DM, et al. Mammalian oocytes are targets for prostaglandin E2 (PGE2) action. Reprod Biol Endocrinol. 2010;8:131.

33. Takahashi T, et al. Cyclooxygenase-2-derived prostaglandin E(2) directs oocyte maturation by differentially influencing multiple signaling pathways. J Biol Chem. 2006;281(48):37117-29.

34. Gordo AC, et al. Mitogen activated protein kinase plays a significant role in metaphase II arrest, spindle morphology, and maintenance of maturation promoting factor activity in bovine oocytes. Mol Reprod Dev. 2001;59(1): 106-14.

35. Sun QY, et al. Regulation of mitogen-activated protein kinase phosphorylation, microtubule organization, chromatin behavior, and cell cycle progression by protein phosphatases during pig oocyte maturation and fertilization in vitro. Biol Reprod. 2002;66(3):580-8.

36. Nuttinck F, et al. PTGS2-related PGE2 affects oocyte MAPK phosphorylation and meiosis progression in cattle: late effects on early embryonic development. Biol Reprod. 2011;84(6):1248-57.

37. Li YH, et al. Localization of angiotensin II in pig ovary and its effects on oocyte maturation in vitro. Theriogenology. 2004;61(2):447-59.

38. Giometti IC, et al. Angiotensin II reverses the inhibitory action produced by theca cells on bovine oocyte nuclear maturation. Theriogenology. 2005; 63(4):1014-25

39. Barreta $\mathrm{MH}$, et al. Evidence that the effect of angiotensin II on bovine oocyte nuclear maturation is mediated by prostaglandins E2 and F2alpha. Reproduction. 2008;136(6):733-40.

40. Siqueira LC, et al. Angiotensin II, progesterone, and prostaglandins are sequential steps in the pathway to bovine oocyte nuclear maturation. Theriogenology. 2012;77(9):1779-87.

41. Ferreira $\mathrm{R}$, et al. The role of angiotensin II in the early stages of bovine ovulation. Reproduction. 2007;134(5):713-9.

42. Yerushalmi GM, et al. The prostaglandin transporter (PGT) as a potential mediator of ovulation. Sci Transl Med. 2016;8(338):338ra68.

43. Furman A, et al. Culture of human granulosa cells from an in vitro fertilization program: effects of extracellular matrix on morphology and cyclic adenosine 3',5' monophosphate production. Fertil Steril. 1986;46(3):514-7.

44. Breyer RM, et al. Prostanoid receptors: subtypes and signaling. Annu Rev Pharmacol Toxicol. 2001:41:661-90

45. Freimann S, et al. Differential expression of genes coding for EGF-like factors and ADAMTS1 following gonadotropin stimulation in normal and transformed human granulosa cells. Biochem Biophys Res Commun. 2005; 333(3):935-43.

46. Freimann S, et al. EGF-like factor epiregulin and amphiregulin expression is regulated by gonadotropins/cAMP in human ovarian follicular cells. Biochem Biophys Res Commun. 2004;324(2):829-34.
47. Richards JS, et al. Ovulation: new dimensions and new regulators of the inflammatory-like response. Annu Rev Physiol. 2002;64:69-92.

48. Buccione R, et al. FSH-induced expansion of the mouse cumulus oophorus in vitro is dependent upon a specific factor(s) secreted by the oocyte. Dev Biol. 1990;138(1):16-25.

49. Tamba S, et al. Timely interaction between prostaglandin and chemokine signaling is a prerequisite for successful fertilization. Proc Natl Acad Sci U S A. 2008;105(38):14539-44.

50. Yodoi R, et al. RhoA/rho kinase signaling in the cumulus mediates extracellular matrix assembly. Endocrinology. 2009;150(7):3345-52.

51. Isobe $T$, et al. The effect of RANTES on human sperm chemotaxis. Hum Reprod. 2002;17(6):1441-6.

52. Tamba S, et al. Expression profiling of cumulus cells reveals functional changes during ovulation and central roles of prostaglandin EP2 receptor in CAMP signaling. Biochimie. 2010;92(6):665-75.

53. Sica A, et al. Monocyte chemotactic and activating factor gene expression induced in endothelial cells by IL-1 and tumor necrosis factor. J Immunol. 1990;144(8):3034-8.

54. Reinecker $\mathrm{HC}$, et al. Monocyte-chemoattractant protein 1 gene expression in intestinal epithelial cells and inflammatory bowel disease mucosa. Gastroenterology. 1995;108(1):40-50.

55. Dahm-Kahler $\mathrm{P}$, et al. Monocyte chemotactic protein-1 in the follicle of the menstrual and IVF cycle. Mol Hum Reprod. 2006;12(1):1-6.

56. Mosher AA, et al. Prostaglandin E2 represses interleukin 1 beta-induced inflammatory mediator output from pregnant human myometrial cells through the EP2 and EP4 receptors. Biol Reprod. 2012;87(1):7. 1-10

57. Kaeoket K, Persson E, Dalin AM. Influence of pre-ovulatory insemination and early pregnancy on the infiltration by cells of the immune system in the sow endometrium. Anim Reprod Sci. 2003;75(1-2):55-71.

58. Tremellen KP, Seamark RF, Robertson SA. Seminal transforming growth factor beta1 stimulates granulocyte-macrophage colony-stimulating factor production and inflammatory cell recruitment in the murine uterus. Biol Reprod. 1998;58(5):1217-25.

59. Troedsson MH, Liu IK, Crabo BG. Sperm transport and survival in the mare: a review. Theriogenology. 1998;50(5):807-18.

60. Alghamdi A, et al. Uterine secretion from mares with post-breeding endometritis alters sperm motion characteristics in vitro. Theriogenology. 2001:55(4):1019-28.

61. Alghamdi AS, Foster DN, Troedsson MH. Equine seminal plasma reduces sperm binding to polymorphonuclear neutrophils (PMNs) and improves the fertility of fresh semen inseminated into inflamed uteri. Reproduction. 2004; 127(5):593-600

62. Wah RM, Anderson DJ, Hill JA. Asymptomatic cervicovaginal leukocytosis in infertile women. Fertil Steril. 1990;54(3):445-50.

63. Kalinski P. Regulation of immune responses by prostaglandin E2. J Immunol. 2012;188(1):21-8.

64. Smith RJ. Modulation of phagocytosis by and lysosomal enzyme secretion from Guinea-pig neutrophils: effect of nonsteroid anti-inflammatory agents and prostaglindins. J Pharmacol Exp Ther. 1977;200(3):647-57.

65. Aronoff DM, Canetti C, Peters-Golden M. Prostaglandin E2 inhibits alveolar macrophage phagocytosis through an E-prostanoid 2 receptor-mediated increase in intracellular cyclic AMP. J Immunol. 2004;173(1):559-65.

66. Wijayagunawardane MP, et al. Local distributions of oviductal estradiol, progesterone, prostaglandins, oxytocin and endothelin-1 in the cyclic cow. Theriogenology. 1998;49(3):607-18.

67. Kodithuwakku SP, Miyamoto A, Wijayagunawardane MP. Spermatozoa stimulate prostaglandin synthesis and secretion in bovine oviductal epithelial cells. Reproduction. 2007;133(6):1087-94.

68. Yousef MS, et al. Sperm binding to oviduct epithelial cells enhances TGFB1 and IL10 expressions in epithelial cells as well as neutrophils in vitro: prostaglandin E2 as a main regulator of anti-inflammatory response in the bovine oviduct. PLoS One. 2016;11(9):e0162309.

69. Talpain E, et al. Characterization of the PGE receptor subtype mediating inhibition of superoxide production in human neutrophils. Br J Pharmacol. 1995;114(7):1459-65

70. Burelout $\mathrm{C}$, et al. Prostaglandin E2 inhibits the phospholipase D pathway stimulated by formyl-methionyl-leucyl-phenylalanine in human neutrophils. Involvement of EP2 receptors and phosphatidylinositol 3-kinase gamma. Mol Pharmacol. 2004;66(2):293-301.

71. Alghamdi AS, Foster DN. Seminal DNase frees spermatozoa entangled in neutrophil extracellular traps. Biol Reprod. 2005;73(6):1174-81. 
72. Brinkmann V, et al. Neutrophil extracellular traps kill bacteria. Science. 2004; 303(5663):1532-5.

73. Marey MA, et al. Bovine oviduct epithelial cells downregulate phagocytosis of sperm by neutrophils: prostaglandin E2 as a major physiological regulator. Reproduction. 2014;147(2):211-9.

74. Tan HN, et al. Cyclooxygenases and prostaglandin $\mathrm{E}$ synthases in preimplantation mouse embryos. Zygote. 2005;13(2):103-8.

75. Chan SY. Effects of prostaglandin E2 and F2 alpha on peri-implantation development of mouse embryos in vitro. Prostaglandins. 1991;42(4):321-36.

76. Sayre BL, Lewis GS. Arachidonic acid metabolism during early development of ovine embryos: a possible relationship to shedding of the zona pellucida. Prostaglandins. 1993:45(6):557-69.

77. Jabbour HN, et al. Expression of COX-2 and PGE synthase and synthesis of PGE(2)in endometrial adenocarcinoma: a possible autocrine/paracrine regulation of neoplastic cell function via EP2/EP4 receptors. $\mathrm{Br} J$ Cancer. 2001;85(7):1023-31.

78. Sales KJ, et al. Cyclooxygenase-2 expression and prostaglandin E(2) synthesis are up-regulated in carcinomas of the cervix: a possible autocrine/paracrine regulation of neoplastic cell function via EP2/EP4 receptors. J Clin Endocrinol Metab. 2001;86(5):2243-9.

79. Arosh JA, Banu SK, McCracken JA. Novel concepts on the role of prostaglandins on luteal maintenance and maternal recognition and establishment of pregnancy in ruminants. J Dairy Sci. 2016;99(7):5926-40.

80. Wasielak M, Kaminska K, Bogacki M. Effect of the conceptus on uterine prostaglandin-F2alpha and prostaglandin-E2 release and synthesis during the periimplantation period in the pig. Reprod Fertil Dev. 2009;21(5):709-17.

81. Weems $Y S$, et al. Effects of prostaglandin $E$ and $F$ receptor agonists in vivo on luteal function in ewes. Prostaglandins Other Lipid Mediat. 2010; 92(1-4):67-72

82. Ashley RL, Arreguin-Arevalo JA, Nett TM. Binding characteristics of the ovine membrane progesterone receptor alpha and expression of the receptor during the estrous cycle. Reprod Biol Endocrinol. 2009;7:42.

83. Nett TM, Niswender GD. Luteal blood flow and receptors for LH during PGF2 alpha-induced luteolysis: production of PGE2 and PGF2 alpha during early pregnancy. Acta Vet Scand Suppl. 1981;77:117-30.

84. Ford SP. Control of blood flow to the gravid uterus of domestic livestock species. J Anim Sci. 1995;73(6):1852-60.

85. Hristovska AM, et al. Prostaglandin E2 induces vascular relaxation by Eprostanoid 4 receptor-mediated activation of endothelial nitric oxide synthase. Hypertension. 2007;50(3):525-30.

86. Asselin E, Bazer FW, Fortier MA. Recombinant ovine and bovine interferons tau regulate prostaglandin production and oxytocin response in cultured bovine endometrial cells. Biol Reprod. 1997;56(2):402-8.

87. Guzeloglu A, Michel F, Thatcher WW. Differential effects of interferon-tau on the prostaglandin synthetic pathway in bovine endometrial cells treated with phorbol ester. J Dairy Sci. 2004;87(7):2032-41.

88. Geisert RD, et al. Embryonic steroids and the establishment of pregnancy in pigs. J Reprod Fertil Suppl. 1990;40:293-305.

89. Spencer TE, Bazer FW. Conceptus signals for establishment and maintenance of pregnancy. Reprod Biol Endocrinol. 2004;2:49.

90. Almog B, et al. Promoting implantation by local injury to the endometrium. Fertil Steril. 2010;94(6):2026-9.

91. Waclawik A, et al. Molecular cloning and spatiotemporal expression of prostaglandin $\mathrm{F}$ synthase and microsomal prostaglandin E synthase-1 in porcine endometrium. Endocrinology. 2006;147(1):210-21.

92. Waclawik A, Ziecik AJ. Differential expression of prostaglandin (PG) synthesis enzymes in conceptus during peri-implantation period and endometrial expression of carbonyl reductase/PG 9-ketoreductase in the pig. J Endocrinol. 2007;194(3):499-510.

93. Waclawik A, et al. Estradiol-17beta, prostaglandin E2 (PGE2), and the PGE2 receptor are involved in PGE2 positive feedback loop in the porcine endometrium. Endocrinology. 2009;150(8):3823-32.

94. Ghosh D, et al. Porcine carbonyl reductase. Structural basis for a functional monomer in short chain dehydrogenases/reductases. J Biol Chem. 2001; 276(21):18457-63.

95. Ashworth MD, et al. Expression of porcine endometrial prostaglandin synthase during the estrous cycle and early pregnancy, and following endocrine disruption of pregnancy. Biol Reprod. 2006;74(6):1007-15.

96. Blitek $A$, et al. Expression of cyclooxygenase- 1 and -2 in the porcine endometrium during the oestrous cycle and early pregnancy. Reprod Domest Anim. 2006;41(3):251-7.
97. Hoggatt J, et al. Prostaglandin E2 enhances hematopoietic stem cell homing, survival, and proliferation. Blood. 2009;113(22):5444-55.

98. Katoh $\mathrm{H}$, et al. COX-2 and prostaglandin EP3/EP4 signaling regulate the tumor stromal proangiogenic microenvironment via CXCL12-CXCR4 chemokine systems. Am J Pathol. 2010;176(3):1469-83.

99. Sherwin JR, et al. Identification of novel genes regulated by chorionic gonadotropin in baboon endometrium during the window of implantation. Endocrinology. 2007;148(2):618-26.

100. Zhou WH, et al. Chemokine CXCL12 promotes the cross-talk between trophoblasts and decidual stromal cells in human first-trimester pregnancy. Hum Reprod. 2008;23(12):2669-79.

101. Weber JA, et al. Prostaglandin E2 secretion by oviductal transport-stage equine embryos. Biol Reprod. 1991;45(4):540-3.

102. Sales KJ, et al. Chorionic gonadotrophin regulates CXCR4 expression in human endometrium via E-series prostanoid receptor 2 signalling to PI3KERK1/2: implications for fetal-maternal crosstalk for embryo implantation. Mol Hum Reprod. 2011;17(1):22-32

103. Sales KJ, et al. Seminal plasma activates cyclooxygenase-2 and prostaglandin E2 receptor expression and signalling in cervical adenocarcinoma cells. Mol Hum Reprod. 2002;8(12):1065-70.

104. Jabbour HN, Boddy SC. Prostaglandin E2 induces proliferation of glandular epithelial cells of the human endometrium via extracellular regulated kinase 1/2-mediated pathway. J Clin Endocrinol Metab. 2003;88(9):4481-7.

105. Banerjee $P$, et al. Chorionic gonadotropin regulates prostaglandin $E$ synthase via a phosphatidylinositol 3-kinase-extracellular regulatory kinase pathway in a human endometrial epithelial cell line: implications for endometrial responses for embryo implantation. Endocrinology. 2009;150(9): 4326-37.

106. Dominguez $F$, et al. Hormonal and embryonic regulation of chemokine receptors CXCR1, CXCR4, CCR5 and CCR2B in the human endometrium and the human blastocyst. Mol Hum Reprod. 2003;9(4):189-98.

107. Gentilini D, et al. PI3K/Akt and ERK1/2 signalling pathways are involved in endometrial cell migration induced by 17 beta-estradiol and growth factors. Mol Hum Reprod. 2007;13(5):317-22.

\section{Ready to submit your research? Choose BMC and benefit from:}

- fast, convenient online submission

- thorough peer review by experienced researchers in your field

- rapid publication on acceptance

- support for research data, including large and complex data types

- gold Open Access which fosters wider collaboration and increased citations

- maximum visibility for your research: over $100 \mathrm{M}$ website views per year

At BMC, research is always in progress.

Learn more biomedcentral.com/submissions 